\title{
2015 Milan Declaration: A Call to Action on Obesity - an EASO Position Statement on the Occasion of the 2015 EXPO
}

\author{
Gema Frühbeck ${ }^{a, b}$ Paolo Sbracciaa, c, d Enzo Nisolia, c, e \\ Euan Woodward ${ }^{a}$ Volkan Yumuk $^{a}$ f Nathalie J. Farpour-Lambert ${ }^{a, g}$ \\ Jason G.C. Halford ${ }^{a}$ h Hermann Toplak ${ }^{a, i}$ Michele O. Carruba ${ }^{a, c, j}$ \\ ${ }^{a}$ European Association for the Study of Obesity, London, UK; ${ }^{b}$ Department of \\ Endocrinology \& Nutrition, Clínica Universidad de Navarra, University of Navarra, \\ IdiSNA, CIBEROBN, Instituto de Salud Carlos III, Pamplona, Spain; ' Società Italiana \\ dell'Obesità", Rome, Italy; ${ }^{d}$ Department of Systems Medicine, University of Rome 'Tor \\ Vergata' and Obesity Center, University Hospital Policlinico Tor Vergata, Rome, Italy; \\ e Department of Medical Biotechnology and Translational Medicine, Center for Study \\ and Research on Obesity, University of Milan, Milan, Italy, ${ }^{\mathrm{f}}$ Division of Endocrinology, \\ Metabolism \& Diabetes, Istanbul University Cerrahpasa Medical Faculty, Istanbul, Turkey; \\ gObesity Prevention and Care Program, Service of Therapeutic Education for Chronic \\ Diseases, Department of Community Health, Primary Care and Emergency, University \\ Hospital of Geneva and University of Geneva, Geneva, Switzerland; hDepartment of \\ Psychological Sciences, University of Liverpool, Liverpool, UK; 'Department of Internal \\ Medicine, Medical University Graz, Graz, Austria; jDepartment of Pharmacology, \\ Chemotherapy and Medical Toxicology, Center for Study and Research on Obesity, \\ School of Medicine, Milan University, Istituto Auxologico Italiano, Milan, Italy
}

\section{Back to the Future}

In June 1999 preceded by a 'Fanfara dei Bersaglieri', a special task force of the Italian army, that seeked to emphasize and symbolize the announcement of a relevant action against obesity, the European Association for the Study of Obesity (EASO) issued the 'Milan Declaration' at the 9th European Congress on Obesity (ECO) held in that city calling for recognition, support, and national action to combat the obesity epidemic. Although in the intervening years substantive progress has been made, our current best remains not good enough, and both new resources and opportunities need to be harnessed and exploited in earnest. With the conviction that experts cannot merely sit back to watch the problem of, and the problems resulting from, obesity unfold [1, 2], EASO together with the Italian Society of Obesity (SIO) presented on June 6 the '2015 Milan Declaration' at the EXPO (Universal Exposition topic Feeding the Planet, Energy for Life) restating that it is time to act (Annex 1, available at $h t t p: / /$ www.karger.com/ProdukteDB/produkte.asp?doi=448234) [3]. Within this, EASO resolves to 
Frühbeck et al.: 2015 Milan Declaration: A Call to Action on Obesity - an EASO Position Statement on the Occasion of the 2015 EXPO

provide leadership, guidance, and support to governments, as part of its mission of facilitating and engaging in actions to reduce the burden of unhealthy excess weight in Europe.

Obesity as a gateway to a multitude of disabling and fatal diseases [4] threatens not only global health care systems but also has the potential to cripple national economies and global development. Thus, obesity must become a top priority across governments; only a multimodal strategy that favors an increased commitment for concerted, coordinated, and specific actions will yield tangible results. To effectively combat the obesity epidemic a more proactive approach is needed. At this stage, to develop and implement programs for prevention, early diagnosis, and treatment is absolutely mandatory [5-11]. Therefore, immediate action and priority for research, innovation, and action should focus on obesity, as both a noncommunicable disease (NCD) itself (not yet universally recognized) and a gateway to type 2 diabetes and other very serious NCDs (now commonly accepted) [2,12-15].

\section{Taking the Patient View into Consideration}

While in many areas of medicine the participation of patients is encouraged, traditionally those who are overweight or have obesity have been excluded. In 2015 the EASO Patient Council expressed their view which emphasized the social dimension of obesity. The council called for respect, acceptance, recognition, and impartial discussion along with shared responsibility to stop further stigmatization of those with obesity (Annex 2, available at $h t t p: / / w w w$. karger.com/ProdukteDB/produkte.asp?doi=448234). Patients want to be involved in the process of obesity-related research, management, and development throughout society. This does not undermine the role of the individual but rather empowers him/her through ownership of the solution as well as the problem. Partnership agreements that are closer to the needs of the individuals and communities are long overdue. Regulatory authorities should incorporate the patient perspective highlighting the need to build and maintain a long-term support system around the individual, including integrated networks of key professionals providing relevant and sufficient help and support.

Whereas numerous studies highlight the relevance of sociocultural factors influencing incidence and prevalence of obesity, few interventions address situational rather than individual factors and also how people with obesity perceive causes of and solutions to their condition. In this context, more attention has to be paid to the interplay between the biomedical aspects and social/situational dimensions of obesity. By labelling obesity a disease, we make it a priority and to some extent address stigmatization, but we cannot escape its societal and environmental causes, otherwise failure remains at hand. The solutions to obesity are to be found within the society and in individuals with obesity, and not merely by physicians. With the paucity of available tools for physicians to combat obesity, regulatory authorities must recognize the environmental as well as biological barriers to treatment success. This requires the inclusion of environmental as well as individual considerations into any thorough riskbenefit analyses of treatment options or evaluation of policy intervention. Not least educational efforts should be assumed by overall society to promote sobriety in food consumption and to avoid food wastefulness. These actions could tackle partly the persuasive and imposing advertisements for food overconsumption. The next 15 years will be a critical period for applying our knowledge, and especially for testing our collective ability to limit the spread and impact of obesity in a way we have failed to since 1999. A major concern that recurs throughout these years, is the rapid spread of obesity among young children [16-18]. A comprehensive multi-stakeholder approach requires a truly successful portfolio of interventions (from prevention to treatment), within a whole population approach, that directly addresses fundamental causes of obesity. Only this will provide the basis for an effective part- 
Frühbeck et al.: 2015 Milan Declaration: A Call to Action on Obesity - an EASO Position Statement on the Occasion of the 2015 EXPO

nership that should at last contain the global spread of obesity and effectively manage its consequences. A Milan 2030 declaration should then not be necessary.

\section{Disclosure Statement}

GF has participated in a Novo Nordisk Obesity Scientific Communication Global Advisory Board Meeting. JCGH declares his involvement as a member of a UK Novo Nordisk and Orexigen Advisory Boards. He is recipient of research funding from Bristol Meyers Squib and the American Beverage Association. All research and consultancy monies go to the University of Liverpool to support research. No industry money is taken for research in the health policy arena. HT has served as an advisor for Vivus and Novo Nordisk and has scientific support from Almased ${ }^{\circledR}$. PS served in Novo Nordisk, Astra Zeneca and Eli Lilly national Advisory Boards.

\section{References}

Frühbeck G: Obesity. Screening for the evident in obesity. Nat Rev Endocrinol 2012;8:570-572.

12 (NCD-RisC) NRFC: Trends in adult body-mass index in 200 countries from 1975 to 2014:a pooled analysis of 1698 population-based measurement studies with $19 \cdot 2$ million participants. Lancet 2016;387:1377-1396.

32015 Milan Declaration: A Call to Action on Obesity. A Statement of the Members of the European Association for the Study of Obesity to EXPO 2015. www.easo.org/2015-milan-declaration-a-call-to-action-on-obesity/ (last accessed July 21, 2016).

4 Frühbeck G, Toplak H, Woodward E, Yumuk V, Maislos M, Oppert JM: Obesity: the gateway to ill health - an EASO position statement on a rising public health, clinical and scientific challenge in Europe. Obes Facts 2013; 6:117-120.

5 Fried M, Yumuk V, Oppert JM, Scopinaro N, Torres AJ, Weiner R, et al: Interdisciplinary European guidelines on metabolic and bariatric surgery. Obes Facts 2013;6:449-468.

6 Yumuk V, Frühbeck G, Oppert JM, Woodward E, Toplak H: An EASO position statement on multidisciplinary obesity management in adults. Obes Facts 2014;7:96-101.

-7 Frühbeck G, Toplak H, Woodward E, Halford JC, Yumuk V: Need for a paradigm shift in adult overweight and obesity management - an EASO position statement on a pressing public health, clinical and scientific challenge in Europe. Obes Facts 2014; 7:408-416.

8 Toplak H, Woodward E, Yumuk V, Oppert JM, Halford JC, Frühbeck G: 2014 EASO Position Statement on the use of anti-obesity drugs. Obes Facts 2015;8:166-174.

-9 Frühbeck G: Bariatric and metabolic surgery: a shift in eligibility and success criteria. Nat Rev Endocrinol 2015;11:465-477.

10 Fried M, Yumuk V, Oppert JM, Scopinaro N, Torres A, Weiner R, et al: Interdisciplinary European guidelines on metabolic and bariatric surgery. Obes Surg 2014;24:42-55.

11 Bray GA, Frühbeck G, Ryan DH, Wilding JP: Management of obesity. Lancet 2016;387:1947-1956.

$\checkmark 12$ Cecchini M, Sassi F, Lauer JA, Lee YY, Guajardo-Barron V, Chisholm D: Tackling of unhealthy diets, physical inactivity, and obesity: health effects and cost-effectiveness. Lancet 2010;376:1775-1784.

13 De Maeseneer J, Roberts RG, Demarzo M, Heath I, Sewankambo N, Kidd MR, et al: Tackling NCDs: a different approach is needed. Lancet.2012;379:1860-1861.

14 Alleyne G, Binagwaho A, Haines A, Jahan S, Nugent R, Rojhani A, et al: Embedding non-communicable diseases in the post-2015 development agenda. Lancet 2013;381:566-574.

15 Dain K: Sustainable financing: the Achilles heel of the non-communicable diseases response. Lancet Diabetes Endocrinol 2015;3:923-925.

16 World Health Organization: Report of the Commission on Ending childhood obesity. 2016. http://apps.who. int/iris/bitstream/10665/204176/1/9789241510066_eng.pdf (last accessed July 21, 2016).

17 Al-Saeed AH, Constantino MI, Molyneaux L, D’Souza M, Limacher-Gisler F, Luo C, et al: An inverse relationship between age of type 2 diabetes onset and complication risk and mortality: the impact of youth-onset type 2 diabetes. Diabetes Care 2016;39:823-829.

18 Twig G, Yaniv G, Levine H, Leiba A, Goldberger N, Derazne E, et al: Body-mass index in 2.3 million adolescents and cardiovascular death in adulthood. N Engl J Med 2016;374:2430-2440. 